\title{
EVALUASI SISTEM PROTEKSI BAHAYA KEBAKARAN PADA GEDUNG BADAN PENANGGULANGAN BENCANA ACEH
}

\author{
Winardi Aramiko'), Mochammad Afifuddin' ${ }^{2)}$, Abdul Munir ${ }^{3)}$ \\ ${ }^{1,2,3)}$ Magister Teknik Sipil, Universitas Syiah Kuala, Banda Aceh, Indonesia \\ Email:winardiaramiko@gmail.com ${ }^{1)}$, m.afifuddin@unsyiah.ac.id ${ }^{2)}$, abdulmunir@unsyiah.ac.id ${ }^{3)}$
}

DOI: http://dx.doi.org/10.29103/tj.v11i2.484

(Received: February 2021 / Revised: March 2021 / Accepted: June 2021)

\begin{abstract}
Abstrak
Kantor Badan Penanggulangan Bencana Aceh (BPBA) merupakan Kantor Pemerintah yang memberikan pelayanan kepada masyarakat dalam pelaksanaan kegiatan penanggulangan bencana secara terencana, terpadu, dan menyeluruh dalam tahapan prabencana, saat tanggap darurat, dan pasca bencana. Salah satu hal yang penting dalam penanggulangan kebakaran adalah Emergency Response. Emergency Response dapat diartikan sebagai kecepatan penanganan kebakarannya, sebagai upaya pencegahan dan penanggulangannya agar manusia, bangunan gedung dan lingkungannya terhindar dari bahaya kebakaran yang lebih luas. Metode yang digunakan mix method menggabungkan antara kualitatif dan kuantitatif dengan pengumpulan data yaitu menggunakan data sekunder berupa peta kota Banda Aceh, Layout Gedung Kantor BPBA, Literatur-literatur, Permen PU, Jurnal yang berkaitan dengan penelitian ini dan data primer yang terdiri dari pengamatan terhadap kondisi Kantor BPBA, wawancara, kuesioner. Responden yang digunakan adalah semua pegawai yang bekerja di Kantor BPBA berjumlah 115 orang dikurangi pilot study 30 orang. Dari analisis data penelitian terhadap 26 (dua puluh enam) variable dapat dijelaskan bahwa ada 7 (tujuh) variable yang mendapat skor kecil atau kurang baik dan dapat diartikan bahwa pada bagian variabel tersebut butuh perhatian untuk dilakukan perubahan. Strategi yang dapat dilakukan berdasarkan analisi SWOT adalah membentuk tim siaga tanggap darurat kebakaran yang dibekali dengan pendidikan dan pelatihan secara terencana terpadu dan menyeluruh; menyusun Standar Operasional Prosedur (SOP) penanggulangan bencana kebakaran berdasarkan peraturan perundang-undangan; melakukan simulasi kebakaran gedung secara rutin dan kontinyu; serta memperkuat sistem proteksi aktif lainnya diantaranya adalah membuat hidran air, alarm kebakaran dan smoke detector.
\end{abstract}

Kata Kunci: Bencana, Emergency Response, Sistem Proteksi, Penanggulangan Kebakaran

\begin{abstract}
The Aceh Disaster Management Agency office is a government office that provides services to the community in implementing disaster management activities in a planned, integrated and comprehensive manner in the pre-disaster, emergency response and postdisaster stages. One of the important things in fire prevention is "Emergency Response". Emergency Response can be interpreted as the speed of handling a fire, as an effort to prevent and overcome it so that people, buildings and their environment are protected from a wider fire hazard. The methodology used is the mix method combining qualitative and quantitative data with data collection, namely using secondary data in the form of a Banda Aceh City Map, BPBA Office Building Layout, literature, Permen $\mathrm{PU}$, journals related to this research and primary data consisting of observations of
\end{abstract}


conditions BPBA office, interview, questionnaire. The respondents used are all employees who work in the BPBA office, amounting to 115 people minus the pilot study of 30 people. From the analysis of research data on 26 (twentysix) variables, it can be explained that there are 7 (seven) variables that score small or poorly and it can be interpreted that those variables need attention to make changes. A strategy that can be carried out based on a SWOT analysis is to form a fire emergency response team that is equipped with education and training in an integrated and comprehensive plan; prepare Standard Operating Procedures (SOP) for fire disaster management based on statutory regulations; conduct building fire simulations routinely and continuously; as well as strengthening other active protection systems, including making water hydrants, fire alarms and smoke detectors.

Keywords: Disaster, Emergency Response, Protection System, Fire Prevention

\section{Latar Belakang}

Kebakaran dapat mengakibatkan kematian dan juga keruntuhan struktur yang membahayakan. Kegagalan pengendalian kebakaran dalam bangunan seringkali terjadi disebabkan karena unsur desain bangunan yang kurang baik. Data Pusat Pengendalian Operasi Penanggulangan Bencana (Pusdalops) BPBA bulan Januari sampai September tahun 2020 terjadi 232 kali kejadian kebakaran pemukiman dengan kerugian mencapai Rp 81.475.000.000, (Delapan puluh satu milyar empat ratus tujuah puluh lima ribu rupiah) dan 203 kali kejadian kebakaran hutan dan lahan. Beberapa kasus kebakaran yang terjadi di Kota Banda Aceh sebelumnya yaitu terbakarnya Gedung Bank Aceh, Ruko 9 unit di depan Masjid Baiturrahman, SPBU Simpang Jam, Gedung Biro Rektorat Universitas Syiah Kuala, serta Hotel 61. Gedung tersebut merupakan fasilitas publik, bahkan salah satu gedung yang terbakar terdapat pekerja yang meninggal.

Kantor Badan Penanggulangan Bencana Aceh (BPBA) terletak di jalan Tgk. Daud Beureueh No. 18 merupakan salah satu kantor pelayanan publik yang memberikan pelayanan kepada masyarakat dalam pelaksanaan kegiatan penanggulangan bencana secara terencana, terpadu, dan menyeluruh dalam tahapan prabencana, saat tanggap darurat, dan pasca bencana (Gubernur Aceh, 2010), oleh karena itu diperlukannya adanya kesiapan manajemen penanggulangan bahaya kebakaran pada bangunan ini, sehingga secara bertahap akan meningkatkan potensi fisik, nilai dan ekonomi kantor tersebut. Tujuan penelitian ini adalah untuk mengetahui penerapan sistem proteksi dalam penanggulangan dan penanganan kebakaran pada bangunan gedung Kantor BPBA dan untuk mengetahui kondisi dan ketersediaan sistem proteksi kebakaran pada bangunan gedung Kantor BPBA.

\section{Metode Penelitian}

\subsection{Subjek dan Objek Penelitian}

Lingkup penelitian adalah adanya kemampuan dalam emergency response yaitu tindakan segera yang harus dilakukan pada saat terjadi darurat kebakaran. Subjek penelitian ini adalah bangunan gedung Kantor Badan Penanggulangan Bencana Aceh (BPBA), yang terletak di Jln. Tgk. Daud Beureueh No. 18 Kuta Alam, Kota Banda Aceh, Provinsi Aceh dengan objek penelitian adalah karyawan yang terdiri dari Aparatur Sipil Negara (ASN), karyawan Tenaga Kontrak/Tenaga Outsourcing yang aktif bekerja pada Kantor Badan Penanggulangan Bencana Aceh (BPBA). 


\subsection{Metode Pengumpulan Data}

\subsubsection{Kuesioner}

Pada penelitian ini alat yang digunakan untuk pengumpulan data adalah kuesioner, di mana berisikan sejumlah pertanyaan yang digunakan untuk memperoleh data dari responden. Kuisioner ini berbentuk check list sebuah daftar, di mana responden hanya membubuhkan tanda check pada kolom yang sesuai. Metode pengumpulan data dilakukan dengan penyebaran kuisioner yang ditujukan kepada karyawan BPBA yang aktif. Metode yang digunakan untuk mengambil sampel dengan menggunakan teknik purposive sampling. Jumlah populasi karyawan BPBA yang diteliti diperlihatkan pada Tabel 1.

Tabel 1 Jumlah populasi penelitian

\begin{tabular}{clcc}
\hline No. & Uraian & Jumlah & Keterangan \\
\hline 1 & ASN & 42 & Orang \\
\hline 2 & Tenaga Kontrak & 63 & Orang \\
\hline 3 & Tenaga Outsourcing & 10 & Orang \\
\hline & Total & 115 & Orang \\
\hline
\end{tabular}

\subsubsection{Observasi}

Observasi dilakukan untuk mengetahui risiko kebakaran yang dapat terjadi pada gedung Badan Penanggulangan Bencana Aceh. Setelah diidentifikasi risiko selanjutnya dapat dilakukan penilaian risiko yang dapat terjadi pada gedung Badan Penanggulangan Bencana Aceh tersebut.

\subsection{Teknik Pengumpulan Data Kuesioner}

Langkah pengumpulan data kuesioner terlebih dahulu menyiapkan kuesioner sebanyak 85 eksemplar. Mengingat banyaknya jumlah kuesioner yang harus dibagi, maka dalam proses pembagian kuesioner kepada responden dilakukan langsung oleh peneliti. Kuesioner disebarkan kepada ASN, Tenaga Kontrak dan Tenaga Outsourching yang aktif bekerja di kantor BPBA mulai dari tahun 2010-2020.

Pembagian kuesioner dilakukan pendampingan, agar bila terdapat pertanyaan yang sulit dimengerti oleh responden dapat diberikan penjelasan. Responden hanya diminta untuk memilih jawaban-jawaban yang telah disediakan dengan memberikan checklist $(\sqrt{ })$ pada kuesioner. Kegiatan penyebaran kuesioner dilakukan dalam rentang waktu 1 bulan. Kuesioner penelitian dirancang atas dua bagian, yaitu kuesioner bagian A bertujuan menanyakan tentang karakteristik responden. Indikator karakteristik responden meliputi jenis kelamin, umur, pendidikan terakhir, jabatan, bidang pekerjaan dan lamanya bekerja.

Pengukuran jawaban kuesioner bagian A dilakukan sesuai dengan kepribadian responden. Kuesioner bagian B bertujuan menanyakan faktor-faktor tentang kondisi dan penanganan sistem proteksi bahaya kebakaran.

Pengukuran jawaban kuesioner bagian B menggunakan skala Likert. Pengumpulan data kuesioner dilakukan dengan menjumpai langsung responden dan memberikan formulir kuesioner. Pembagian kuesioner dilakukan oleh peneliti sendiri dengan malakukan pendampingan agar bila terdapat pertanyaan yang sulit dimengerti oleh responden dapat diberikan penjelasan. 


\subsection{Teknik Analisis Data}

\subsubsection{Skala Likert}

Skala Likert juga merupakan alat untuk mengukur atau mengumpulkan data dengan cara menjawab item butir-butir pertanyaan. Tidak ada masalah untuk memberikan angka 5 untuk yang tertinggi dan skor 1 untuk yang terendah atau sebaliknya. Setiap jawaban dihubungkan dengan bentuk pernyataan atau dukungan sikap yang diungkapkan dengan kata-kata (Riduwan dan Sunarto, 2014).

Tabel 2 Skala likert

\begin{tabular}{clc}
\hline No. & \multicolumn{1}{c}{ Alternatif Jawaban } & Skor \\
\hline 1 & Sangat Baik & 5 \\
\hline 2 & Baik & 4 \\
\hline 3 & Kurang Baik & 3 \\
\hline 4 & Tidak Baik & 2 \\
\hline 5 & Sangat Tidak Baik & 1 \\
\hline
\end{tabular}

Sumber: Riduwan dan Sunarto (2014)

\subsubsection{Pilot Study}

Pilot study adalah istilah kolektif untuk setiap kelompok sampel yang digunakan untuk pra uji suatu survey kuesioner sebelum pengumpulan data. Sebelum pengambilan data sumber, pilot study dilakukan untuk mengedit kuesioner survey guna memastikan keakuratan dan kemudahan pemahaman kuesioner (Muhammad Tajuddin et al., 2016). Pengukuran skala tanpa didahului dengan uji coba merupakan riset yang tidak baik. Setidak-tidaknya penelitian uji coba (pilot study) harus dilakukan untuk memastikan realibilitas dan validitas pengukuran skala yang akan digunakan. Suatu pengukuran harus memiliki kedua kualitas ini jika ingin dikategorikan sebagai pengukuran yang bermanfaat. Setiap hasil pengukuran selalu mengandung elemen kesalahan di dalamnya. Kesalahan yang masuk ke dalam pengukuran dapat berasal dari berbagai sumber seperti ketidakjelasan dalam merumuskan pertanyaan pada kuesioner, kesalahan teknis yang dilakukan peneliti, atau kesalahan responden ketika menjawab pertanyaan (Morissan, 2012). Jumlah responden untuk uji coba diisyaratkan minimal 30 orang di mana dengan jumlah minimal ini, distribusi skor/nilai akan lebih mendekati kurva normal (Arikunto, 2010).

\subsubsection{Statistical Product and Service Solution (SPSS)}

SPSS merupakan salah satu program komputer statistik yang mampu memproses data statistik secara tepat dan cepat menjadi berbagai output yang dikehendaki para peneliti (Sudjana, 2005). SPSS dapat membaca berbagai jenis data atau memasukkan data secara langsung ke dalam SPSS data editor, bagaimanapun struktur dari file data mentahnya, maka dalam data editor SPSS harus dibentuk dalam bentuk baris (cases) dan kolom (variabel). Dahulu SPSS digunakan untuk olah data statistik pada ilmu sosial, SPSS mengalami perkembangan dan penggunaannya semakin kompleks untuk berbagai bidang ilmu, seperti ekonomi, psikologi, pertanian, teknologi, industry, dan lain-lain (Larry, 2012). 


\subsubsection{Analisis SWOT (Strength, Weakness, Opportunity, Threat)}

Alat yang dipakai untuk menyusun faktor-faktor strategis adalah matriks SWOT. Matriks ini dapat menggambarkan secara jelas interaksi antara Internal Faktor Analysis Strategic (IFAS) dan External Factor Analysis Strategic (EFAS). Interaksi bagaimana peluang dan ancaman eksternal yang dihadapi dapat disesuaikan dengan kekuatan dan kelemahan yang dimilikinya. Matriks ini dapat menghasilkan empat set kemungkinan alternatif strategis sebagai solusi (Rangkuti, 2017).

SWOT dimanfaatkan untuk menilai segala kekuatan dan kelemahan dari berbagai sumber daya yang dimiliki oleh perusahan dan semua kesempatan eksternal dan tantangan yang dihadapi (Jogiyanto HM, 2005). Analisa ini pada dasarnya dipakai untuk meneliti dan menentukan hal berikut:

a) Kuat (sehingga dapat dioptimalkan)

b) Lemah (sehingga dapat segera dibenahi)

c) Kesempatan (untuk dimanfaatkan)

d) Ancaman dari luar (untuk diantisipasi)

Tabel 3 Interaksi antar faktor matriks SWOT

\begin{tabular}{|c|c|c|}
\hline $\begin{array}{ll}\text { EFAS } & \text { IFAS } \\
\end{array}$ & Kekuatan (Strength) & Kelemahan (Weakness) \\
\hline Peluang (Opportunity) & Strategi SO & Strategi WO \\
\hline Ancaman (Threats) & Strategi ST & Strategi WT \\
\hline
\end{tabular}

\section{Hasil dan Pembahasan}

Responden penelitian ini terdiri dari ASN, Tenaga Kontrak dan Tenaga Outsourching yang aktif bekerja pada Kantor Badan Penanggulangan Bencana Aceh, yang berjumlah 85 responden dengan jumlah aktifitas bidang sekretariat adalah sebanyak 36 orang dengan bobot sebesar $42,4 \%$, bidang pencegahan dan kesiapsiagaan sebanyak 10 orang dengan bobot sebesar $11,8 \%$, bidang kedaruratan dan logistik sebanyak 20 orang dengan bobot sebesar $23,5 \%$, bidang rehabilitasi dan rekonstruksi sebanyak 9 orang dengan bobot sebesar $10,6 \%$, bidang tenaga bantuan pusdalops sebanyak 6 orang dengan bobot sebesar $7,1 \%$ dan tenaga pelayanan kebersihan sebanyak 4 orang dengan bobot 4,7\%. Lebih jelasnya dapat dilihat pada Gambar 1.

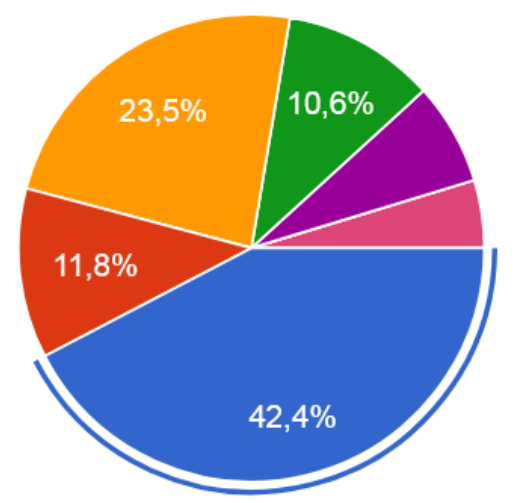

Sekretariat

Pencegahan dan Kesiapsiagaan

Kedaruratan dan Logistik

Rehabilitasi dan Rekonstruksi

Tenaga Bantuan Pusdalops

Tenaga Pengamanan

Tenaga Pelayanan Kebersihan

Gambar 1 Karakteristik responden berdasarkan aktifitas/bidang 
Responden terdiri dari 85 orang, dengan lamanya bekerja selama $<1$ tahun sebanyak 2 orang dengan bobot sebesar 2,4\%, lamanya bekerja 1-5 tahun sebanyak 34 orang dengan bobot sebesar $34 \%$, dan yang bekerja diatas 5 tahun sebanyak 49 orang dengan bobot sebesar 57,6\%. Karakteristik keseluruhan para responden berdasarkan lamanya bekerja di BPBA lebih jelasnya dapat dilihat pada Gambar 2.
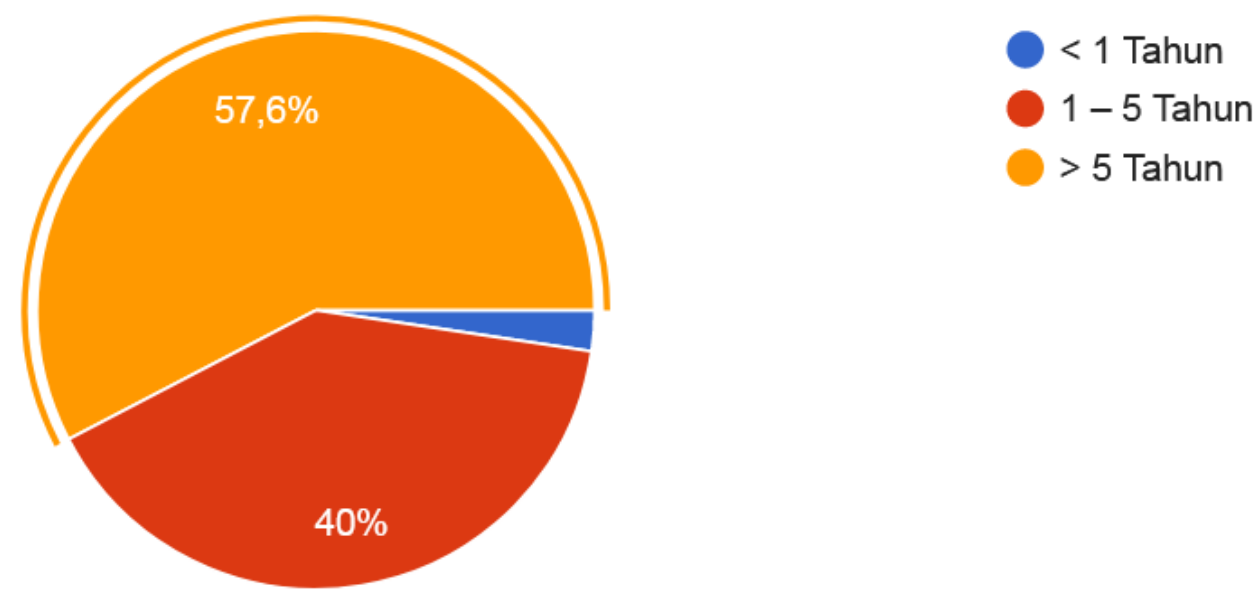

Gambar 2 Karakteristik Responden Berdasarkan Lamanya Bekerja

Responden terdiri dari 85 orang, dengan pendidikan terakhir SMA/Sederaja adalah 35 orang dengan bobot sebesar $41,2 \%$, D3/Sederajat sebanyak 5 orang dengan bobot sebesar 5,9\%, S1/Sederajat sebanyak 30 orang dengan bobot sebesar $30,3 \%$, dan S2 sebanyaknya 15 orang dengan bobot sebesar 17,6\%. Karakteristik responden berdasarkan pendidikan terakhir lebih jelasnya dapat dilihat pada Gambar 3.
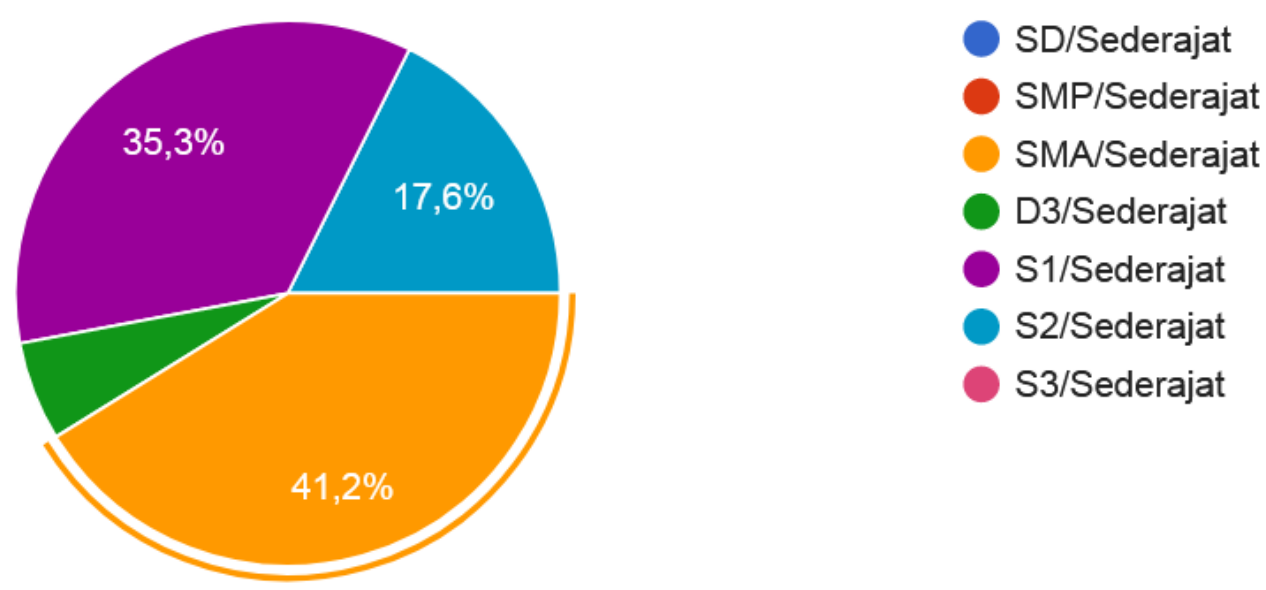

Gambar 1 Karakteristik Responden Berdasarkan Pendidikan Terakhir

\subsection{Alat Pemadam Api Ringan (APAR)}

Observasi dilakukan disemua bagian Kantor Badan Penanggulangan Bencana Aceh. Untuk ketersediaan APAR berjumlah 10 unit. Pada bangunan lantai 1 terdapat 6 APAR dan lantai 2 bangunan terdapat 4 unit APAR dan semuanya berjenis Clean Agent. Dari hasil observasi terhadap kondisi APAR dapat dilihat pada Tabel 4 berikut: 
Tabel 4 Kondisi APAR

\begin{tabular}{|c|c|c|c|}
\hline No & Elemen yang dianalisis sesuai & Kondisi & $\begin{array}{l}\text { Persentase } \\
\text { Kesesuaian }\end{array}$ \\
\hline 1 & $\begin{array}{l}\text { APAR diletakkan pada posisi yang } \\
\text { mudah dilihat, mudah dicapai, mudah } \\
\text { diambil }\end{array}$ & $\begin{array}{l}\text { APAR berjumlah } 10 \text { unit, } \\
\text { berwarna merah ditempatkan pada } \\
\text { standing boot sehingga mudah } \\
\text { dilihat, dicapai dan diambil }\end{array}$ & $100 \%$ \\
\hline 2 & APAR diperiksa dua kali dalam setahun & $\begin{array}{lcr}\text { Semua } & \text { APAR } & \text { hanya diperiksa } \\
\text { sekali dalam } & \text { setahun, } & \text { tanpa } \\
\text { dibuktikan } & \text { dengan } & \text { label } \\
\text { pemeriksaan pada APAR } & \\
\end{array}$ & $50 \%$ \\
\hline 3 & $\begin{array}{l}\text { Petunjuk cara pemakaian APAR harus } \\
\text { dapat dibaca dengan jelas }\end{array}$ & $\begin{array}{l}\text { Semua APAR terdapat cara } \\
\text { penggunaan yang ditempelkan } \\
\text { pada tabung APAR, pada standing } \\
\text { boot juga ditempelkan cara } \\
\text { penggunaan dan pemakaian APAR } \\
\text { dengan mudah dan sangat jelas }\end{array}$ & $100 \%$ \\
\hline 4 & $\begin{array}{l}\text { Pemasangan dan penempatan APAR } \\
\text { harus sesuai dengan jenis dan } \\
\text { penggolongan kebakaran }\end{array}$ & $\begin{array}{l}\text { Semua APAR berjenis Clean } \\
\text { Agent }\end{array}$ & $100 \%$ \\
\hline 5 & $\begin{array}{l}\text { Penempatan jarak antara satu APAR } \\
\text { dengan APAR lainnya tidak melebihi } 15 \\
\text { meter, kecuali ditetapkan oleh ahli } \\
\text { pengawasan K3 }\end{array}$ & $\begin{array}{l}\text { Keseluruhan APAR berjumlah } 10 \\
\text { unit, ditempatkan pada lantai } 1 \text { dan } \\
\text { lantai } 2 \text { bangunan dan jarak antara } \\
\text { APAR tidak lebih dari } 15 \text { meter }\end{array}$ & $100 \%$ \\
\hline 6 & $\begin{array}{l}\text { Setiap APAR harus dipasang } \\
\text { menggantung pada dinding dengan } \\
\text { penguatan sengkang atau ditempatkan } \\
\text { dalam lemari atau peti (box) yang tidak } \\
\text { terkunci, atau pada tempat yang tidak } \\
\text { langsung bersentuhan dengan lantai } \\
\text { bangunan }\end{array}$ & $\begin{array}{l}\text { Semua APAR ditempatkan pada } \\
\text { standing boot sehingga mudah } \\
\text { dilihat, dicapai dan diambil }\end{array}$ & $100 \%$ \\
\hline 7 & $\begin{array}{l}\text { Warna dasar tanda pemasangan APAR } \\
\text { yaitu merah }\end{array}$ & $\begin{array}{l}\text { Terdapat tanda pemasangan } \\
\text { APAR berwarna merah }\end{array}$ & $100 \%$ \\
\hline 8 & $\begin{array}{l}\text { Pada tabung APAR terdapat klasifikasi } \\
\text { kebakaran yang sesuai dengan jenis } \\
\text { kebakaran }\end{array}$ & $\begin{array}{l}\text { Semua APAR } \\
\text { klasifikasi kebakaran }\end{array}$ & $100 \%$ \\
\hline 9 & $\begin{array}{l}\text { Sebelum dipakai segel pengaman harus } \\
\text { dalam keadaan baik dan penutup tabung } \\
\text { terpasang kuat }\end{array}$ & $\begin{array}{l}\text { Semua APAR memiliki segel dan } \\
\text { penutup yang tidak rusak }\end{array}$ & $100 \%$ \\
\hline 10 & $\begin{array}{l}\text { Lubang penyemprot tidak tersumbat dan } \\
\text { selang tahan tekanan tinggi serta tidak } \\
\text { bocor }\end{array}$ & $\begin{array}{l}\text { Lubang pada selang tidak } \\
\text { tersumbat dan selang tidak rusak }\end{array}$ & $100 \%$ \\
\hline 11 & $\begin{array}{l}\text { Isi tabung gas sesuai dengan tekanan } \\
\text { yang dipergunakan dan dijaga tetap } \\
\text { penuh }\end{array}$ & $\begin{array}{l}\text { Semua APAR memiliki tekanan } \\
\text { penuh }\end{array}$ & $100 \%$ \\
\hline
\end{tabular}

\subsection{Pendapat Kuesioner}

Evaluasi sistem proteksi dalam upaya pencegahan bahaya kebakaran dalam penelitian ini ditinjau dari lima faktor dan 26 variabel, yaitu penyediaan sarana pemadam kebakaran dan sarana evakuasi, penyebab kebakaran, pelatihan penanggulangan bencana, perencanaan tanggap darurat, dan perilaku. Dari hasil pendapat para responden dan hasil dilakukannya olah data ada beberapa hal yang 
masih kurang baik diantaranya tangki air tersedia dengan volume 2.000 liter tetapi ketersediaan air sering tidak cukup dan tidak memadai, kondisi para perokok dalam kategori kurang baik karena masih merokok sembarang baik di dalam maupun di luar ruangan, kondisi posisi penempatan mesin generator set (genset) yang dapat menyebabkan kebakaran sangat tidak baik karena bersebelah langsung dengan parkiran kendaraan roda dua, pelatihan penanggulangan kebakaran menggunakan APAR masih sangat minim sebagian besar para karyawan/ti belum bisa menggunakan APAR, begitu juga dengan frekuenasi pelatihan yang masih sangat kurang, simulasi kegiatan penanggulangan kebakaran sangat jarang dilakukan.

\subsection{Analisa Strategi Kantor Badan Penanggulangan Bencana Aceh}

Strategi di Kantor Badan Penanggulangan Bencana Aceh dianalisis dengan menggunakan analisa secara SWOT. Matriks ini menghasilkan empat solusi alternative strategi sesuai dengan potensi serta kondisi internal dan eksternal.

Tabel 5 SFAS (Strategi Factors Analysis Summary)

\begin{tabular}{|c|c|c|}
\hline & Kekuatan (S) & Kelemahan $(W)$ \\
\hline EFAS & $\begin{array}{l}\text { 1. Badan Penanggulangan } \\
\text { Bencana Aceh adalah Instansi } \\
\text { yang melaksanakan } \\
\text { penanggulangan bencana } \\
\text { secara terintegrasi } \\
\text { 2. Struktur dalam Instansi Badan } \\
\text { Penanggulangan Bencana } \\
\text { Aceh (BPBA) } \\
\text { 3. Penyusunan standar } \\
\text { operasional prosedur (SOP) } \\
\text { menghadapi kebakaran } \\
\text { 4. Ketersediaan sumber daya } \\
\text { manusia dan finansial dalam } \\
\text { mengurangi dampak risiko } \\
\text { Komitmen Pimpinan untuk } \\
\text { melakukan penguatan } \\
\text { tanggap darurat bencana }\end{array}$ & 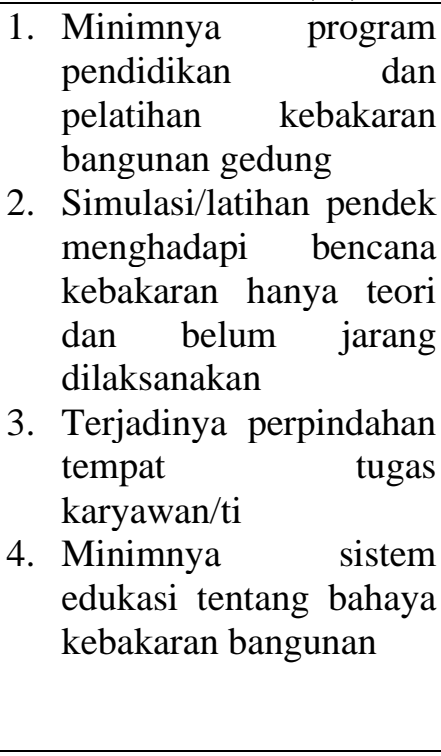 \\
\hline Peluang $(\mathrm{O})$ & Strategi (SO) & Strategi $(\mathrm{WO})$ \\
\hline $\begin{array}{l}\text { 1. Personil yang } \\
\text { menguasai ilmu } \\
\text { kebakaran dilapangan } \\
\text { 2. Adanya evaluasi dari } \\
\text { pimpinan SKPA } \\
\text { terhadap disiplin ilmu } \\
\text { 3. Koordinasi dengan } \\
\text { Dinas Pemadam dan } \\
\text { Penyelamatan } \\
\text { Kebakaran setempat } \\
\text { Dukungan yang sangat } \\
\text { baik dari seluruh } \\
\text { karyawan/ti }\end{array}$ & $\begin{array}{l}\text { 1. Mengajukan usulan } \\
\text { perekrutan tenaga yang } \\
\text { menguasai ilmu menghadapi } \\
\text { kebakaran bangunan gedung } \\
\text { 2. Adanya evaluasi dari } \\
\text { pimpinan SKPA terhadap } \\
\text { disiplin ilmu } \\
\text { 3. Membentuk Tim Pembuatan } \\
\text { Standar Operasional } \\
\text { 4. Prosedur (SOP) kebakaran } \\
\text { Mengoptimalkan penyediaan } \\
\text { alat pemadam api ringan } \\
\text { yang memadai sesuai dengan } \\
\text { peraturan dan standar yang } \\
\text { berlaku }\end{array}$ & $\begin{array}{l}\text { 1. Perekrutan Tenaga yang } \\
\text { menguasai ilmu } \\
\text { menghadapi kebakaran } \\
\text { bangunan gedung } \\
\text { 2. Membentuk tim siaga } \\
\text { tanggap darurat } \\
\text { kebakaran yang dibekali } \\
\text { dengan pendidikan dan } \\
\text { pelatihan }\end{array}$ \\
\hline
\end{tabular}




\begin{tabular}{|c|c|c|}
\hline $\operatorname{Ancaman}(T)$ & Strategi (ST) & Strategi $(W T)$ \\
\hline 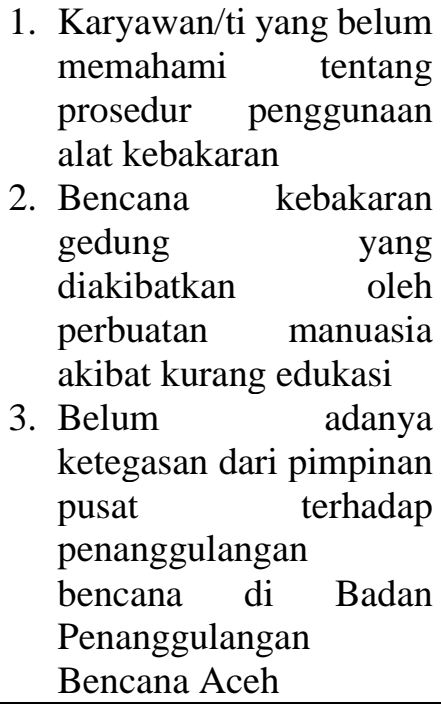 & $\begin{array}{l}\text { 1. Perlunya standar operasional } \\
\text { atau pengamatan langsung } \\
\text { terhadap kondisi peralatan } \\
\text { 2. Meningkatkan kerjasama } \\
\text { pengawasan dan } \\
\text { pengendalian dengan instansi } \\
\text { terkait kebakaran } \\
\text { 3. Menyediakan dana khusus } \\
\text { kegiatan pengurangan risiko } \\
\text { penanggulangan bahaya } \\
\text { kebakaran }\end{array}$ & $\begin{array}{l}\text { 1. Mereviuw dan } \\
\text { melaksanakan simulasi } \\
\text { rutin kebakaran } \\
\text { bangunan gedung } \\
\text { dengan keterlibatan } \\
\text { semua pihak baik } \\
\text { pemerintah maupun } \\
\text { swasta dan memastikan } \\
\text { tepat sasaran } \\
\text { 2. Memperkuat manajemen } \\
\text { penanggulangan bencana } \\
\text { secara terencana, terpadu, } \\
\text { dan menyeluruh }\end{array}$ \\
\hline
\end{tabular}

Hasil interaksi IFAS - EFAS bobot tertinggi adalah alternative strategi Weakness - Opportunity (WO), yaitu strategi menanggulangi kelemahan dan memanfaatkan peluang yang tersedia. Adapun matriks analisis SWOT menanggulangi kelemahan dan memanfaatkan peluang dapat dilihat pada Table 5 .

Tersedia sebelas strategi dalam empat alternatif strategi (SO, WO, ST, dan WT). Untuk mendukung dan membantu proses kesiapan Sistem Proteksi Dalam Upaya Pencegahan Bahaya Kebakaran Pada Bangunan Gedung Badan Penanggulangan Bencana Aceh bisa digunakan beberapa strategi, diantaranya:

Tabel 6 Strategi alternatif

1. Strategi S-O 1. Mengajukan usulan perekrutan tenaga yang menguasai ilmu menghadapi kebakaran bangunan gedung

2. Adanya evaluasi dari pimpinan SKPA terhadap disiplin ilmu

3. Membentuk Tim Pembuatan Standar Operasional Prosedur (SOP) kebakaran

4. Mengoptimalkan penyediaan alat pemadam api ringan yang memadai sesuai dengan peraturan dan standar yang berlaku

2. Strategi W-O 1. Perekrutan Tenaga yang menguasai ilmu menghadapi kebakaran bangunan gedung

2. Membentuk tim siaga tanggap darurat kebakaran yang dibekali dengan pendidikan dan pelatihan

3. Strategi S-T 1. Perlunya standar operasional atau pengamatan langsung terhadap kondisi peralatan

2. Meningkatkan kerjasama pengawasan dan pengendalian dengan instansi terkait kebakaran

3. Menyediakan dana khusus kegiatan pengurangan risiko penanggulangan bahaya kebakaran

4. Strategi W-T 1. Mereviuw dan melaksanakan simulasi rutin kebakaran bangunan gedung dengan keterlibatan semua pihak baik pemerintah maupun swasta dan memastikan tepat sasaran

2. Memperkuat manajemen penanggulangan bencana secara terencana, terpadu, dan menyeluruh 
Badan Penanggulangan Bencana Aceh yang terbentuk Qanun Aceh Nomor 6 Tahun 2010 tentang Susunan Organisasi dan Tata Kerja Badan Penanggulangan Bencana Aceh. Badan Penanggulangan Bencana Aceh melaksanakan penanggulangan bencana secara terintegrasi dalam tahapan prabencana, saat tanggap darurat, dan pasca bencana, harus memikirkan strategi dalam lingkungan perkantorannya. Berdasarkan analisa SWOT sebagai bentuk awal yang telah dilakukan perumusannya dapat untuk dijadikan menjadi kriteria, kriteria yang dapat menjadi acuan disimpulkan menjadi 4 strategi, diantaranya adalah : membentuk tim siaga tanggap darurat kebakaran yang dibekali dengan pendidikan dan pelatihan secara terencana terpadu dan menyeluruh, menyusun Standar Operasional Prosedur (SOP) dengan mempertimbangkan standardisasi dan kebutuhan penyelenggaraan penanggulangan bencana berdasarkan peraturan perundang-undangan, melakukan simulasi kebakaran gedung secara rutin dan kontinyu, serta memperkuat sistem proteksi aktif lainnya diantaranya adalah membuat hidran air, alarm kebakaran dan smoke detector.

\section{Kesimpulan dan Saran}

\subsection{Kesimpulan}

Kesimpulan dari analisis data penelitian terhadap 26 (dua puluh enam) variable dapat dijelaskan bahwa ada beberapa variable yang mendapat skor kecil atau kurang baik dan dapat diartikan bahwa pada bagian variabel tersebut butuh perhatian untuk dilakukan perubahan diantaranya adalah kondisi ketersediaan air di tempat kerja untuk memadamkan api dengan nilai FI sebesar 0,61; kondisi para perokok sebelum membuang puntungnya ditempat kerja dengan nilai FI sebesar 0,58; kondisi posisi penempatan mesin generator set (genset) yang harus jauh dari parkiran kendaraan dengan nilai FI sebesar 0,55; kesiapan pelatihan penanggulangan kebakaran menggunakan APAR dengan nilai FI sebesar 0,60; kesiapan pelatihan penanggulangan kebakaran dengan menggunakan air dengan nilai FI sebesar 0,59; frekuensi secara periodik latihan penanggulangan kebakaran dengan nilai FI sebesar 0,56; kesiapan simulasi menghadapi kebakaran dengan nilai FI sebesar 0,60 .

Hasil analisis SWOT perlu beberapa perubahan dan strategi, berikut beberapa alternatif strategi perbaikan ke depan diantaranya adalah membentuk tim siaga tanggap darurat kebakaran yang dibekali dengan pendidikan dan pelatihan secara terencana terpadu dan menyeluruh, menyusun Standar Operasional Prosedur (SOP) dengan mempertimbangkan standardisasi dan kebutuhan penyelenggaraan penanggulangan bencana berdasarkan peraturan perundang-undangan, melakukan simulasi kebakaran gedung secara rutin dan kontinyu, serta memperkuat sistem proteksi aktif lainnya diantaranya adalah membuat hidran air, alarm kebakaran dan smoke detector.

\subsection{Saran}

Berdasarkan hasil yang didapat dapat dikemukakan untuk mengoptimalkan sistem proteksi pada Badan Penanggulangan Bencana Aceh, maka disarankan Badan Penanggulangan Bencana Aceh harus secara rutin dan kontinyu dalam melakukan simulasi penanganan kebakaran gedung. Melakukan pengecekan rutin dan berkala terhadap alat sistem proteksi seperti APAR pada Instansi yang berwenang. 


\section{Daftar Kepustakaan}

Arikunto, S, 2010. Prosedur Penelitian Pendidikan Suatu Pendekatan Praktik. Jakarta: Rineka Cipta.

Bruck, D. and Thomas, I, 2010. Interactions Between Human Behaviour and Technology: Implications for Fire Safety Science. Fire Technology, 46(4). doi: 10.1007/s10694-010-0161-1.

Gubernur Aceh, 2010. Qanun Aceh Nomor 6 Tahun 2010 Tentang Pembentukan Organisasi dan Tata Kerja Badan Penanggulangan Bencana Aceh. Pemerintah Aceh, Indonesia.

Gwynne, S. M. V. et al, 2012. Understanding and representing staff pre-warning delay. Journal of Fire Protection Engineering, 22(2). doi: $10.1177 / 1042391512436785$.

Gwynne, S. M. V., Boswell, D. L. and Proulx, G, 2009. Understanding the effectiveness of notification technologies in assisting vulnerable populations. Journal of Fire Protection Engineering, 19(1). doi: 10.1177/1042391508095094.

Jogiyanto., H. M, 2005. Sistem Informasi Strategik untuk Keunggulan Kompetitif. Yogyakarta, Penerbit Andi.

Larry, R, 2012. Jurus Kilat Mahir SPSS: Panduan Lengkap SPSS Data Statistik Untuk Pemula. Jakarta, Dunia Komputer.

Meacham, B. J, 1999. Integrating human behavior and response issues into fire safety management of facilities. Facilities, 17. doi: 10.1108/02632779910278719.

Morissan, M, 2012. Metode Penelitian Survei. Edisi I. Penerbit Kencana, Jakarta, Indonesia.

Muhammad Tajuddin, 2016. Kesuksesan sistem informasi perguruan tinggi dan good university governance: (sebuah kajian empiris di perguruan tinggi swasta). in Kesuksesan sistem informasi perguruan tinggi dan good university governance: (sebuah kajian empiris di perguruan tinggi swasta).

Nilsson, D. and Johansson, A, 2009. Social influence during the initial phase of a fire evacuation-Analysis of evacuation experiments in a cinema theatre. Fire Safety Journal, 44(1). doi: 10.1016/j.firesaf.2008.03.008.

Ramli, S, 2010. Petunjuk Praktis Manajemen Kebakaran (Fire Management). Dian Rakyat.

Rangkuti, 2017. Analisis Swot - Teknik Membedah Kasus Bisnis. Cara Perhitungan Bobot, Rating, dan OCAI. Penerbit PT. Gramedia Pustaka Utama.

Riduwan, Sunarto, 2014. Pengantar Statistika. Penerbit Alfabeta, Bandung, Indonesia

Sudjana, 2005. Metode Statistika. Edisi I. Bandung: Tarsito. 
Menteri Tenaga Kerja dan Transmigrasi, 1980. Peraturan Menteri Tenaga Kerja dan Transmigrasi No: PER.04/MEN/1980 Tentang Syarat-syarat Pemasangan Dan Pemeliharaan Alat Pemadam Api Ringan. Kementerian Tenaga Kerja dan Transmigrasi

Menteri Pekerjaan Umum, 2009. Peraturan Menteri Pekerjaan Umum No: 20/PRT/M/2009 Tentang Pedoman Teknis Manajemen Proteksi Kebakaran di Perkotaan. Kementerian Pekerjaan Umum. 